\title{
An Assessment of Customers' Adaptability to Technological Innovations in Kenya's Banking Industry: Effects of Customers Perceptions
}

\author{
Dr. Grace Akinyi Musa ${ }^{1 *} \quad$ Pamela Atieno Moro ${ }^{2} \quad$ Sandra Beldine Otieno ${ }^{3}$ \\ 1. Department of Accounting and Finance, the Technical University of Kenya, Kenya \\ 2. Department of Management Science and Technology, the Technical University of Kenya, Kenya \\ 3.Data analyst- Data Coding and Interpretation. Nairobi, Kenya
}

\begin{abstract}
To keep abreast of changes in the global financial environment, Kenya has experienced a weighty transformation in most of its industries, including the banking sector. The major changes witnessed in the sector have been immense advances in financial technological innovations which are as a result of uproars in the global financial environment. With the rapid and extensive increase in technological innovations, new distribution channels in the financial sector are coming up speedily. These include Automated Teller Machines, Mobile Banking and Internet Banking. These have made accessibility of money easy to bank customers since they can get it at their convenience. The evenly spread of Automated Teller Machines in most parts of the country has further made it easier for bank customers to withdraw and deposit money and/ or cheques at their convenience. These facts notwithstanding, it has been observed that most Kenyans bank customers have not fully embraced the technological innovations. This has been largely caused by bank customers' negative perceptions towards technological innovations. As a result, most bank customers have clung to the old traditions which make them resistant and non-adaptable to technological innovations. These have been witnessed in the behaviors of most bank customers whereby they are still queuing in the banking halls despite the availability of Mobile Banking, Automated Teller Machines, and Internet Banking. The general objective of the study was an assessment of customers' adaptability to the technological innovations in Kenya's banking industry with the effects of customers' perceptions. A specific objective was derived from the main objective. Two questionnaires were designed which were used to collect the views of the respondents. The population of the study comprised of senior managers from ten Commercial banks and bank customers employed in different organizations and those who were self-employed. The banking customers were selected at random. A cross-sectional ex-post facto research design was applied. Findings revealed a significant relationship between technological innovations and customers' adaptability in Kenya's banking sector. The significant moderating effect of customers' perceptions on the relationship between technological innovations and customers' adaptability in Kenya's banking sector. The study suggested that bank management should intensify their campaign on awareness stressing the benefits that accrue from the use of financial technological innovations; tighten their securities especially in ATMs and Internet Banking and charge minimum amounts for the services. Prior studies hitherto concentrated on the benefits of technological innovations to the banking sectors and their employees; the extent by which technological innovations improved the financial performance of the banking sector and developed Kenya's technological industry. The studies greatest contribution to knowledge is that to attain maximum technological innovations, bank customers' negative perceptions and resistance to change should undergo a complete overhaul.
\end{abstract}

Keywords: Automated Teller Machines, Internet banking, Mobile Banking, financial Technological Innovations, Banking Sector, Customers Perceptions

DOI: $10.7176 /$ RJFA/11-10-02

Publication date:May $31^{\text {st }} 2020$

\section{Introduction}

The main objective of the study was an assessment of bank customers' adaptability to technological innovations in the banking sector with the effects of customers' perceptions. It is worth noting that Kenya as an economy has been faced with two major challenges; the realization of Kenya Vision $2030(\mathrm{GoK}, 2007)$, and the speedy global technological innovations. Further, the government has listed Banking as one of the sectors under financial services that are seen to contribute massively to the realization of the Vision. This has called for the development of technological innovations in the banking sector. Furthermore, it has seen the banking sector experiencing a profound transformation owing to the changes in the global financial environment including; the introduction of Mobile Banking, Automated Teller Machines (ATMs), and Internet Banking. Technological innovations in the banking sector were expected to benefit bank customers in various ways. For example, Internet banking systems would enable bank customers to have easy access to their accounts and general information on bank products and services (Gupta S. , 2013). These would be achieved through the use of bank websites without the inconvenience of sending letters, faxes, original signatures, and telephone confirmations (Panida \& Sunsern, 2012). Further, 
internet banking is the type of services through which bank customers could request information and carry out most mobile retail banking services such as balance reporting, inter-account transfers bill payment via telecommunication network at their doorsteps (Dube, Tofara, \& Langton, 2009).

These facts notwithstanding, research has shown that most of Kenya's bank customers have developed negative perceptions towards these technological innovations. For instance, most bank customers, despite having ATMs cards are still lining up in the banking halls to either deposit or withdraw cash (source). Moreover, other bank customers have been forced to travel from far areas to only come and queue in the baking halls for services that would be available at their doorsteps, if only they embraced the use of internet banking. It is now clear that despite the existence of technologies offered by Kenyan banks, most bank customers' have-not embraced them. This pointed out to relative failures by Kenyan bank management in their campaign to; create awareness of the benefits accruing from technological innovations, thus attracting more bank customers to the changes. Low adaptability by the bank customers to technological innovations has been taken as a serious drawback to Kenya's banking sector (source). This is more so especially now that Kenya has devolved its Government and is looking forward to the realization of Kenya vision 2030. For Kenya to achieve this dream, all the four pillars of Kenya vision 2030 must be accomplished including strategies on the use of technology within the banking sector. (GoK, 2007).

\subsection{Statement of the problem}

The main problem of the study was that despite the availability of technological innovations adopted by Kenyan banks, most bank customers had failed to acclimatize by these new developments. Research has shown that most of Kenya's bank customers have pointed out on the insecurity which came up with ATMs, Mobile Banking and Internet Banking. For instance, most bank customers have continuously lost their monies to robbers and carjackers who have been forcing them to withdraw maximum amounts using their ATM cards, others complained of losing huge sums through hackers of their mobile and internet bank accounts. Besides, most bank customers have complained of the high fees levied by banks on the services rendered through the technological innovations. For instance, the use of internet banking with regards to local payments and international payment via PayPal, charges more than one thousand Kenya shillings per single transfer (Standard Chartered Bank, 2020). Moreover, the majority of these customers are not financially disciplined and has found themselves overspending their monies laxities since they can withdraw at any time from everywhere. This has left most of them without money for their basic needs. This has resulted in most of such customers withdrawing from the use of internet banking, mobile banking, and ATM cards.

This turmoil would be detrimental to Kenya's economy which has devolved its government and is in serious need of the technological innovations for speedy developments of these Counties. Further, for the realization of Kenya vision 2030; all sectors of the economy need complete overhaul with developments, economically, socially, politically, and technologically. This dream can only be realized if all organizations and their human resources including bank customers embraced technological innovations. It was expected that the achievement of full banking financial and technological innovations would enable all bank customers 'use their ATM cards, mobile, and internet banking to withdraw or deposit cash at their convenience.

It was also expected that this would go a long way avoiding overcrowding in the baking halls, hence fulfilling the Corona Virus Disease 2019 (Covid-19) pandemic rule which calls for social distancing (World Health Organization,2020). Further, since the ATMs and banking agents are spread in all parts of the country, it would allow most bank customers ease of making their banking transactions. Moreover, Internet banking was expected to be advantageous since bank customers could make transactions of different types from anywhere in the world. This would be of the essence and especially during emergencies and sickness such as the Covid-19 pandemic where access to the banks may have been restricted due to lockdowns (World Health Organization, 2020).

With these facts notwithstanding, it has been observed that many Kenyans especially bank customers have not adapted to the innovations and technological changes. This has been evidenced by the fact that Kenyan banking halls are always full of the bank customers queuing in the banking halls. Cases in question are where most bank customers have continuously queued on the banking halls to either withdraw or deposit cash when some of them even had ATM cards in their wallets or handbags. Others who have access to the internet have failed to register for internet banking, equally, those who have mobile phones have failed to register for mobile banking; a situation that could save lives due to this pandemic and make it convenient to both banks and their customers. These scenarios pointed out to relative failures by Kenyan banks management to change the negative perceptions that had been developed by most bank customers towards technological innovations. This serves a clear indicator of a major drawback by Kenyan banks management that some serious works need to be undertaken to introduce more bank customers into the banking technological innovations.

Prior studies on banking technological innovations have focused mainly on the benefits which banks receive such as lowering operational costs which leads to earning higher profits (Mateka, Gogo, \& Omagwa, 2016). The previous studies have also focused on the extent bank employees adapted to technological innovations (Gupta \& 
Yadav, 2017) and investigating the effects of smart technology on customer dynamics (Foroudi, Gupta, Sivarajah, $\&$ Broderick, 2018). The studies, however, failed to address the extent to which bank customers' have adapted to technological innovations which have been a serious omission since bank customers, human resources, are the most valuable non- current assets in any organization (Achoki, 2013). Kenyan banks are therefore mandated to ensure the satisfaction of their customers based on adaptability to technological innovations including; Mobile Banking, Internet Banking, and ATM services with effects of customers' perceptions. This has been lacking, hence the justification of the current study.

\section{Theoretical Review}

This consisted of theoretical and empirical reviews where past theories and studies were compared to current studies and gaps highlighted therein.

\subsection{The theory of planned behavior}

This Theory was developed by (Ajzen, 1991). The theory states that attitude towards behavior, subjective norms, and perceived behavioral control, together shape an individual's behavioral intentions and behaviors. That is, the banking system operates within stipulated rules and regulations which must be adhered to before performing any action. The theory is important to the current study in that before engaging in internet banking and obtaining an ATM card, a bank customer is required to furnish the bank with certain details. That is banks have no obligation to force their customers into using the innovations and technologies. At the same time bank customers can only effect transactions such as withdrawing or depositing money via ATMs when they have ATM cards or they must have identity cards when effecting transactions over the counters.

\subsection{Theory of Reasoned Action}

This theory was developed by (Ajzen \& Fishbien, 1980). It sought to explain the reasons which lead an individual to behave in a given manner. The Theory is important to the current study as it has been incorporated to explain the relationship between bank customers and adaptability with the technological innovations. According to the TRA, the following facts applied; that, bank customers 'negative perceptions towards banking technological innovations may have affected their adaptability towards innovation and technologies. The fact that most bank customers believed that using internet banking and ATMs were financially risky. They would rather queue in the banking halls rather than lose all their monies to robbers.

\subsection{Theory of Consumer Behavior}

This theory was developed by William Stanley Jevon (1870), a British Economist. It explains the consumer's behavior given different alternatives. The Theory focuses on a consumer whose aim is to maximize utility. The Theory is important to the current study because the technological innovations are utilities that should be maximized. The consumers, in this case, are the bank's customers who are being encouraged by the bank authorities to maximize satisfaction (utility) from the technological innovations given internet banking, ATMs, and mobile banking. The Theory of Consumer Behavior is important to the current study since it explains the relationships that exist with all the study variables given the availability of internet banking, Automated Teller Machines, and mobile banking. The three theories used informed the study variables.

\section{Empirical Review}

The revolution in information and communication technologies has become central to developments in the banking and financial services industry (Furst et al, 1998). New technologies in banking are already transforming the financial sector, and the traditional banking landscape is set to rapidly change in many years to come. Safety features, such as advanced cryptography and biometrics, will help protect against bank frauds, and remote applications will make it easier than ever to do transactions without visiting any bank. ATMs transformed the bank tech system when they were first introduced in 1967 (Gordon, 2017). The next revolution in ATMs is likely to involve contactless payments. In Kenya, most bank customers can now conduct contactless ATM transactions using a Smartphone. Some ATM innovations are already available in such banks as ABSA Kenya where, for example, biometric authentication is already in use and eye recognition is in place within the bank ATMs. These technologies can help overall bank security by protecting against ATM frauds. The mobile and digital transformation in the banking system has been in use in Kenya for a while and growth is already explosive. Banks are investing heavily in digital banking technology, in which customers use mobile, web or digital platforms to use banking services (Csiszar, 2019).

Numerous studies on banking innovation and technologies have focused mainly on the benefits derived by banks, customers' experiences while using banking innovations and technologies, amongst others. The studies ignored banking customers' adaptability to technological innovations adopted by banks. There was thus the creation of conceptual gaps as shown in the prior studies therein. 
(Foroudi, Gupta, Sivarajah, \& Broderick, 2018), investigated the effects of smart technology on customer dynamics. Their findings from this study reflected on the role of customer dynamics and customers' experiences in embracing the innovative application of smart technologies in a retail setting. Note that smart technologies here meant smart mobile phones, tablets, and wearable. The results and implications also contributed to the understanding of the determinants that affect customer dynamics and customer experience when making use of smart technologies and customers' experiences. The focus of the current study on the other hand is on the adaptability of internet banking and ATM services offered by banks.

A study conducted by (Patel \& Connolly, 2015), on factors influencing the adoption of Information technology showed the importance of social factors and characteristics of adopters that affected users' behavior to adopt technology. (Gupta \& Yadav, 2017) on the other hand, analyzed the Impact of Electronic Banking and Information Technology on the Employees of Banking Sector. His findings revealed a significant impact between the employees of the banking sector and electronic banking and information technology. The study concentrated on the adoption of new technology by employees of the banking sector. This contrasted sharply with the focus of the current study which concentrated on the adaptability by the banking customers.

A study conducted in India by (Firdous \& Farooqi, 2017)on the impact of internet banking service quality on customer satisfaction. Results revealed that internet banking service quality dimensions have a significant impact on the customer satisfaction of internet banking customers.(Mateka, Gogo, \& Omagwa, 2016) assessed effects of internet banking on the financial performance of listed Commercial banks in Kenya and the key finding of the study revealed that internet banking has a positive influence on bank incomes, operating costs, and loan book, and customers' deposits.

(Salamah, 2016), investigated the Impact of Electronic Banking Services on Bank Transactions and his findings revealed that electronic services have contributed to increasing both the financial activity of the bank as well as the number of its clients. In the banking sector, professional training can be given to banking officials, so that they can effectively work on the electronic system. The satisfaction has covertly impact $t$ a customer inclination towards electronic banking and electronic banking has positively influenced the banking transaction.

These past studies, however, had no universal agreements. The current study therefore has come handy to fill the void created. This is because technological innovations introduced by banks are meant to be used by bank customers. Failure by bank customers to adapt to them would render their use futile. It is thus important to conduct an assessment on the extent bank customers' have adapted to technological innovations in Kenya's economy with the effects of customers' perceptions.

\subsection{Conceptual Framework}

The conceptual framework depicted the relationships between the independent variable, Banking Innovations and technologies which comprise of (internet banking, mobile banking and ATMs transactions); moderating variable Bank Customers Perceptions which comprise of (negative perceptions and resistance to change) and dependent variable Adaptability by Bank Customers which comprised of (level of awareness, political stability, and costs of technological innovations).

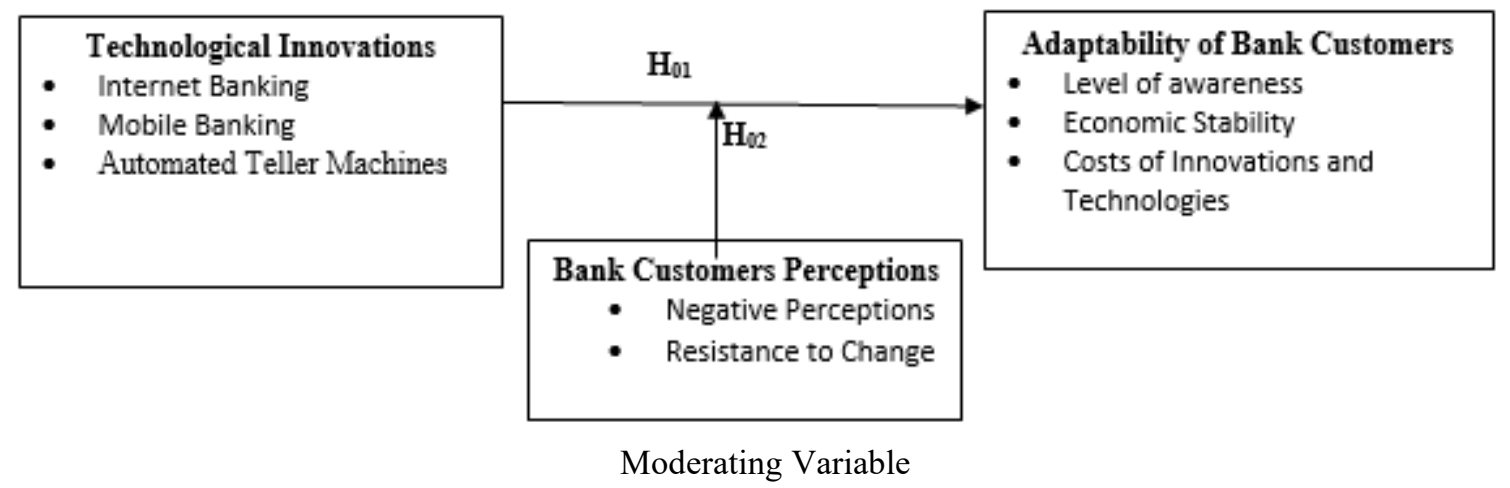

Figure 1: Conceptual Framework

Source: Author

Ho1: The relationship between banking technological innovations on customers' adaptability.

Ho2: The moderating effect of customer's perceptions on the relationship between technological innovations and customers' adaptability.

\section{Methodology}

The study adopted an ex-post-facto cross-sectional design. A cross-sectional design since data was collected only once. In an ex-post facto design, attempts are made to determine the influence of a variable on another variable 
and test a state using statistical hypothesis testing techniques (Tunji, 2012). The study sought to assess customers' adaptability with innovations and technologies in the banking industry, the design was deemed appropriate. The study relied heavily on primary data obtained from structured questionnaires to managers and bank customers. A simple random sampling method was used to identify the respondents. The questionnaires were administered to 100 bank customers and 20 bank managers in Nairobi Central Business District (CBD). Data was analyzed and the following was established.

\subsection{Data Analysis and Interpretation}

The study had an $88 \%$ response rate since 106 out of 120 questionnaires were answered appropriately. Table 1: Model Summary of Technological Innovations and Customers Adaptability

\begin{tabular}{|c|c|c|c|c|c|c|}
\hline \multirow{2}{*}{$\frac{\text { Regression model }}{\text { Logistic regression }}$} & & & \multicolumn{3}{|c|}{ Statistic } & Value \\
\hline & & & & Number & of obs & 106 \\
\hline & & & & LR chi2 & (8) & 15.324 \\
\hline & & & & Prob $>\mathrm{cl}$ & ii 2 & 0.031 \\
\hline \multirow[t]{2}{*}{$\underline{\text { Log likelihood }=-181.734}$} & & & & Pseudo I & $\mathrm{R} 2$ & 0.544 \\
\hline & Coeff. & Std. Err. & $\mathbf{Z}$ & $\mathbf{P}>\mathbf{Z}$ & {$[95 \%$ Conf. } & Interval] \\
\hline Technological Innovations & 0.542 & 0.169 & 2.232 & 0.025 & 0.012 & 0.613 \\
\hline const. & -0.692 & 0.139 & -7.06 & 0 & -1.125 & -0.659 \\
\hline
\end{tabular}

The summary statistics in Table 1 is divided into two sections: the goodness of fit section and the coefficient section. In the goodness-of-fit part, we see LR Chi $2=15.324$ with a $p$-value of 0.031 . Chi2 value and its p-value are used to check for the significance of the model fit. Since the p-value is less than 0.05 , the Chi 2 value implies that the model is significant and adequately fits the data. That is, the model is a significant fit than a model with no predictor (s), an empty model.

The Pseudo R2 value is used to check for the extent to which the independent variable (s) influences the dependent variable. Therefore, the value of the Pseudo $\mathrm{R} 2=0.544$ implies that variations in the independent variable (Technological Innovations) only account for $54.4 \%$ of the total variations in the log likelihood of a customer's adaptability. This means that the remaining $45.6 \%$ of the variation is accounted for by factors not explained by or included in the model.

In the coefficient section, we have coefficients for each of the predictor variables with the corresponding standard errors, z-statistics, p-values and the 95\% confidence intervals. Summary statistics for this section shows that the coefficient of Technological Innovations was 0.542, and that of the constant coefficient was -0.692 . Based on these coefficient values, we obtained the following logistic regression equation:

$$
\log _{e}\left(\frac{P(Y)}{1-P(Y)}\right)=-0.692+0.542 X \ldots
$$

To test for the effect of Technological Innovations, of importance is the coefficient value for Technological Innovations. From table 2, the $\mathrm{Z}$ statistic of the coefficient of Technological Innovations was found to be 2.232 with a corresponding p-value $0.025(<0.05)$. Based on the obtained p-value, the coefficient was considered to be significant at 0.05 level of significance.

This means that any improvement in the aspects of Technological Innovations by one unit would increase the $\log$ odds of a student choosing accounting, as a major, by 0.542 . From the coefficient of Technological Innovations, the odds ratio of choosing accounting corresponding to a unit increase in the levels of Technological Innovations is given by $e^{0.542}=1.719$.

Since the p-value was less than 0.05 , we inferred that there is a significant proportional change in the odds of a customer's adaptability by 1.719 due to a unit increase in the levels of Technological Innovations. Since the pvalue is less than 0.05 , the study rejected the null hypothesis at $5 \%$ level of significance about the non-significance of the effect of Technological Innovations on customers' adaptability.

This decision implied that Technological Innovations has a significant influence on bank customer's adaptability to the advancements made in the banking industry. The null hypothesis developed was rejected. 
Table 2: Moderation Effect of Customers' Perception on their Adaptability

\begin{tabular}{|c|c|c|c|c|c|c|c|}
\hline \multicolumn{8}{|c|}{ Information Criterion Change Statistics } \\
\hline Block & $\mathbf{L L}$ & LR & Df & Pr $>$ LR & & & BIC \\
\hline 1 & -181.293 & 12.473 & 2 & 0.056 & & 3.586 & 379.843 \\
\hline 2 & -177.524 & 7.533 & 1 & 0.003 & & 3.051 & 378.061 \\
\hline \multicolumn{8}{|c|}{ Coefficients for Moderation Effect of Customers' Preference } \\
\hline & & Coeff. & Std. Err. & $\mathbf{Z}$ & $\mathbf{P}>\mathbf{Z}$ & {$[95 \%$ Conf. } & Interval] \\
\hline \multicolumn{2}{|c|}{ Technological Innovations } & 0.44 & 0.168 & 2.135 & 0.002 & 0.031 & 0.729 \\
\hline \multicolumn{2}{|c|}{ Customers' Preference } & 0.645 & 0.231 & 2.627 & 0.010 & 0.134 & 0.922 \\
\hline \multirow{2}{*}{\multicolumn{2}{|c|}{$\begin{array}{l}\text { Interaction Variable } \\
\text { const. }\end{array}$}} & -0.567 & 0.25 & -1.979 & 0.015 & -0.945 & -0.005 \\
\hline & & -0.821 & 0.155 & -6.833 & 0.000 & -1.186 & -0.656 \\
\hline
\end{tabular}

In this test, the interaction variable was added to the model. The table has been divided into two parts: information criterion change statistics and coefficients table for moderation effect of Customers' Preferences, the study has the likelihood ratio change due to the addition of the interaction variable. The significance of this change is tested by the p-value in the Block 2 model. From the table, the study observed that the change in the LR due to the addition of the interaction variable is significant as shown by the P-value $(=0.003)$, which is less than 0.05 .

This confirmed that the addition of the interaction variable significantly improved the model at a $5 \%$ significance level. In the coefficients' section, we have the coefficients for Technological Innovations, Customers' Preference, and the interaction variable. Both Technological Innovations and Customers' Preference were significant since their respective p-values, 0.002 and 0.010 , were significant at $5 \%$ level of significance. Of interest was, however, the significance of the added interaction variable. From the output, the study observed that the interaction variables were significant at a $5 \%$ significance level since the corresponding $\mathrm{p}$-value $=0.015$ was less than 0.05 .

Based on the significances of the both likelihood ratio change and the interaction variable, the study rejected the null hypothesis H02. Customers' Preference had no significant moderating effect on the relationship between Technological Innovations and students' choice of Accounting Major. The study therefore, concluded that Customers' Preference had a significant moderating effect on the relationship between Technological Innovations and Customers' Adaptability.

\subsection{Findings}

The study's first objective was an assessment of bank customers' adaptability to the technological innovations in Kenya's banking industry. The study established a significant relationship between banking technological innovations and bank customers' adaptability. The study's first objective was an assessment of bank customers' adaptability to the technological innovations in Kenya's banking industry. The study established a significant relationship between banking technological innovations and bank customers' adaptability. The study's second objective was the moderating effect of customers' perceptions on the relationship between banking technological innovations and bank customers' adaptability. The study established a significant moderating effect of customers' perceptions on the relationship between banking technological innovations and bank customers' adaptability. These findings differed with the findings of prior studies with respect to concept, context, methodology and theory as follows:

The findings of a study conducted by (Firdous \& Farooqi, 2017) revealed a positive significant relationship between the role of customer dynamics and Customers experiences in embracing innovative application of smart technologies in retail setting. This finding was in agreement with the finding of the current study. However, a conceptual gap was created since the focus of the current study was on bank customers' adaptability to the use of internet banking, mobile banking and ATMs services offered by banks. The study went further to explain reasons for low adaptability of technological innovations such as insecurity, high costs associated with the banking innovations and technologies. The use of other variables bridged the Conceptual gap created.

Findings of a study by (Gupta \& Yadav, 2017) revealed a significant impact between the employees of banking sector and electronic banking and information Technology. This finding was consistent with that of the current study since bank employees were expected to train bank customers. This means that if bank employees adapted to the technologies, they were likely to convince the customers positively towards adaption in the use of ATMs, mobile banking and internet banking. Contextual gap is filled by a new focus on bank customers.

Findings by (Mateka, Gogo, \& Omagwa, 2016) revealed that internet banking had a positive influence on bank incomes, operating costs, loan book, and customers' deposits. However, the current study assessed the extent of adaption of bank customers from the technological innovations adopted by banks such as of ATMs, internet and mobile banking. A contextual gap was filled by addressing different population

The study's second objective was the moderating effect of customers' perceptions on the relationship between banking technological innovations and bank customers' adaptability. The study established a significant 
moderating effect of customers' perceptions on the relationship between banking technological innovations and bank customers' adaptability. This finding implied that most of Kenya's bank customers were still resistant to change in as far as technological innovations were concerned. The result was observed in the negative attitudes that most banking customers developed towards banking technological innovations. The study also established that most banking customers were not ready to adapt to the banking technological innovations due to the high level of insecurity and exorbitant cost associated with internet banking, mobile banking, and the use of ATMs.

\subsection{Limitations, Justifications, and Suggestions for Future Researchers}

Conceptual Limitations: The study used internet banking, mobile banking, and Automated Teller Machines as its variables for the adaptation of bank customers to innovations and technologies. There were other variables that the study could have used such as information technology. However, this did not compromise the quality of the research findings, since these were the key variables for banking innovations and technologies. Future researchers should consider exploring areas not covered by the current research such as the use of Mpesa services.

Contextual Limitations: The study was limited to bank customers at the Nairobi Central Business. It was expected that Nairobi being the capital city of Kenya where most major commercial banks are situated, would have vast bank customers from all walks of life. This was expected to give representative views of all Kenyan bank customers. Future researchers should consider conducting their researches on other Kenyan major cities or in the whole country.

Theoretical Limitations: The study applied three behavioral theories including, the theory of planned behavior, the theory of Reasoned Action, and the theory of Consumer Behavior. These theories informed the study variables. Future researchers should consider using theories that were not considered in this study.

Methodological Limitations: The study applied ex-post-facto cross-sectional research design and simple stratified random sampling based on multiple regression models. This was based on the fact that data was collected and analyzed within a short period. Future researchers should consider using a longitudinal research design with a census-based on models that were not considered in this study.

\section{Contribution to the Body of Knowledge}

Bank Management: The study is expected to act as 'a wakeup call' to bank management as they will learn that all is not well with their customers and or technological innovations. Kenya's Commercial Bank managements are expected to ensure that all their employees are fully trained so that in return bank customers are also trained. Bank management will be expected to see the necessity of reinforcing their security measures which will be expected to guard the safety of their customers' transactions including safety of the bank customers' money.

Kenya's Government: Will be expected to ensure that the banking industry is fully developed in terms of technological innovations. This will be more so towards achievement of Kenya vision 2030, where development of the banking sector has been listed as one of the main pillar of the vision (Government of Kenya, 2007).

Bank Customers: The study is expected to act as a complete transformation on bank customers negative perceptions towards banking technological innovations. The study will be expected to shed light towards the advantages which accrue from the use of the facilities, enabling more customers embrace banking technological innovations.

\section{Conclusion}

Internet banking and Mobile banking: Bank management should ensure that they train their employees on the proper use of these facilities. This is more so since their employees are the ones having first hand communication with the bank customers. Bank employees should be taken through the whole process of internet banking. This is with a view to their employees offering the right training to the bank customers, showing customers benefits that come with internet banking and more so during crises such as covid-19 where there could be complete lock down or any other emergencies such as other ailments or being in the rural areas and there arise an urgent need of money. The bank management should take advantage of the current situation of corona virus pandemic to train and introduce more customers to internet banking as it is a real necessity at this time.

ATMS: Bank management should provide full security on this facility. For example there should be permanent groups of armed security in posted in the ATMs 24/ 7. This will give bank customers confidence in depositing and or withdrawing money from the ATMs. This is so because the main problem raised by most bank customers for not using the facilities was insecurity. Where possible the ATMs should be located as attachments within the banking halls for full security. Bank management should also ensure that CCTVs are attached within the ATMs. This will serve as a prevention measure against robbers and since they will fear for being identified.

In summary, for bank customers to fully embrace technological innovations, bank management is mandated to ensure that customers' negative perceptions and resistance to change are completely eradicated. Kenyan bank management has to instill confidence in their customers. This will go a long way in ensuring that customers 'adaptability to technological innovations is attained. This should be with a view of not only retaining the few 
users to the banking technological innovations, but also attracting more customers to the practice.

The economic pillar as envisioned in Kenya's Vision 2030 acknowledges the need to develop energetic and internationally competitive financial services in order to achieve high levels of savings and financing of investments in Kenya (Kenya Vision, 2030). Banking sector has been listed as one of the sectors under financial services that are seen to contribute massively to the realization of Vision 2030. This dream can only be met if bank customers fully adapt to the technological inventions.

\section{Acknowledgement}

My heartfelt thanks goes to Madam Pamela Atieno Moro for immensely contributing towards this journal by bring in the information technology knowledge to the paper without which it could not have been possible to incorporate the technological innovation expertise. I also most sincerely thank my analyst, Sandra Beldine Otieno very much for ensuring that perfect methodology and data analysis was manifested in this manuscript. My endless thanks go to my family headed by my husband, Engineer Amos Akelo for creating a conducive atmosphere to conduct this study. I would also like to acknowledge Professor Alexander, the chief editor of IISTE together with the review team for the enormous work done by pointing out the areas to be corrected which made the final manuscript perfect. I also thank IISTE fraternity for their quick response towards reviewing the manuscript in record time. Last but not least, I thank The Almighty God for granting me good protection and health even during the global difficult time of covid-19 pandemic. To God be the glory, Amen.

\section{References}

Achoki, G. (2013). Human Resource Accounting. Retrieved August 14th, 2019, from http://globaljournals.org/GJMBR../1-human-resource-accounting.pdf

Ajzen. (1991). Organizational Behaviour and Human Decision Processes. Journal of Implications for Employers' Education and Trainng, 54(1), 50-64.

Ajzen, I., \& Fishbien, M. (1980). Understanding Attitudes and Predicting Social Behaviour. Accounting Education.

Csiszar, J. (2019, April 14). GOBankingRates. Retrieved from gobankingrates.com.

Dube, T., Tofara, C., \& Langton, R. (2009). Adoption and use of Internet Banking in Zimbabwe:An Exploratory Study. Journal of Internet Banking and Commerce, 14, 1-13.

Firdous, S., \& Farooqi, R. (2017). Impact of Internet Banking Service Quality on Customer Satisfaction. Journal of Internet Banking and Commerce, 1-17.

Foroudi, P., Gupta, S., Sivarajah, U., \& Broderick, A. (2018). Investigating the effects of Smart Technology on Customer Dynamics and Customer Experience. Computers in Human Behavior, 271-282.

Gordon, C. (2017, Fourth Quarter). Mobile Payments Today. Retrieved from www.mobilepaymentstoday.com.

Gupta, S. (2013). The Mobile Banking and Payment Revolution. European Financial Review, 3-6.

Gupta, S., \& Yadav, A. (2017). The impact of Electronic Banking and Information Technology on the Employees of Banking Sector. Sage journals. doi:https://doi.org/10.1177/2393957517736457

Mateka, M., Gogo, J., \& Omagwa, J. (2016). Effects of Internet Banking on Financial Performance of listed Commercial Banks in Kenya. American Journal of Finance, 1(2), 53-71.

Panida, S., \& Sunsern, L. (2012). A case study of internet banking security of mainland Chinese banks:A customer perspective. (pp. 189-195). Phuket, Thailand: IEEE.

Patel, H., \& Connolly, R. (2015). Factors Influencing Technology Adoption:A review. Information Management in the Networked Econonomy:Issues \& Solutions, 416-431.

Salamah, N. H. (2016). Impact of Electronic Banking Services on Bank Transactions. International Journal of Economics and Finance, 111-122.

Tunji, S. T. (2012). Accounting Information as an aid to management decision making. International Journal of Management and Social Sciences Research. 